\title{
Performance of Mesoporous HZSM-5 and Silicalite-1 Coated Mesoporous HZSM-5 Catalysts for Deoxygenation of Straw Fast Pyrolysis Vapors
}

Eschenbacher, Andreas; Goodarzi, Farnoosh; Saraeian, Alireza; Kegnæs, Søren; Shanks, Brent H.; Jensen, Anker Degn

Published in:

Journal of Analytical and Applied Pyrolysis

Link to article, DOI:

10.1016/j.jaap.2019.104712

Publication date:

2020

Document Version

Peer reviewed version

Link back to DTU Orbit

Citation $(A P A)$ :

Eschenbacher, A., Goodarzi, F., Saraeian, A., Kegnæs, S., Shanks, B. H., \& Jensen, A. D. (2020). Performance of Mesoporous HZSM-5 and Silicalite-1 Coated Mesoporous HZSM-5 Catalysts for Deoxygenation of Straw Fast Pyrolysis Vapors. Journal of Analytical and Applied Pyrolysis, 145, [104712].

https://doi.org/10.1016/j.jaap.2019.104712

\section{General rights}

Copyright and moral rights for the publications made accessible in the public portal are retained by the authors and/or other copyright owners and it is a condition of accessing publications that users recognise and abide by the legal requirements associated with these rights.

- Users may download and print one copy of any publication from the public portal for the purpose of private study or research.

- You may not further distribute the material or use it for any profit-making activity or commercial gain

- You may freely distribute the URL identifying the publication in the public portal 


\section{Journal Pre-proof}

Performance of Mesoporous HZSM-5 and Silicalite-1 Coated Mesoporous HZSM-5 Catalysts for Deoxygenation of Straw Fast Pyrolysis Vapors

Andreas Eschenbacher, Farnoosh Goodarzi, Alireza Saraeian,

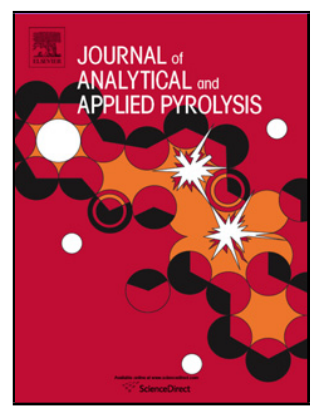
Søren Kegnæs, Brent H. Shanks, Anker D. Jensen

$\begin{array}{ll}\text { PII: } & \text { S0165-2370(19)30696-5 } \\ \text { DOI: } & \text { https://doi.org/10.1016/j.jaap.2019.104712 } \\ \text { Reference: } & \text { JAAP 104712 } \\ \text { To appear in: } & \text { Journal of Analytical and Applied Pyrolysis } \\ \text { Received Date: } & 9 \text { September } 2019 \\ \text { Revised Date: } & \text { 11 October } 2019 \\ \text { Accepted Date: } & \text { 12 October } 2019\end{array}$

Please cite this article as: Eschenbacher A, Goodarzi F, Saraeian A, Kegnæs S, Shanks BH, Jensen AD, Performance of Mesoporous HZSM-5 and Silicalite-1 Coated Mesoporous HZSM-5 Catalysts for Deoxygenation of Straw Fast Pyrolysis Vapors, Journal of Analytical and Applied Pyrolysis (2019), doi: https://doi.org/10.1016/j.jaap.2019.104712

This is a PDF file of an article that has undergone enhancements after acceptance, such as the addition of a cover page and metadata, and formatting for readability, but it is not yet the definitive version of record. This version will undergo additional copyediting, typesetting and review before it is published in its final form, but we are providing this version to give early visibility of the article. Please note that, during the production process, errors may be discovered which could affect the content, and all legal disclaimers that apply to the journal pertain.

(C) 2019 Published by Elsevier. 


\section{Performance of Mesoporous HZSM-5 and Silicalite-}

\section{Coated Mesoporous HZSM-5 Catalysts for}

\section{Deoxygenation of Straw Fast Pyrolysis Vapors}

Andreas Eschenbacher ${ }^{\mathrm{a}, \ddagger}$, Farnoosh Goodarzi $^{\mathrm{b},{ }^{\ddagger}}$, Alireza Saraeian ${ }^{c}$, Søren Kegnces ${ }^{b}$, Brent $H$. Shanks, , Anker D. Jensen ${ }^{a, *}$

${ }^{a}$ DTU Chemical Engineering, Technical University of Denmark, Søltofts Plads 229, 2800 Kgs.

Lyngby, Denmark

${ }^{b}$ DTU Chemistry, Technical University of Denmark, Kemitorvet Building 207, 2800 Kgs.

Lyngby, Denmark

'Department of Chemical and Biological Engineering, Iowa State University, Ames, IA 50011, United States

\section{Corresponding Author:}

* aj@kt.dtu.dk (Anker Degn Jensen) 
"These authors contributed equally.

\section{Highlights}

- Coating of mesoporous ZSM-5 with Silicalite-1 to passivate external acid sites

- Catalyst deactivation was followed during vapor upgrading in tandem micropyrolyzer

- Coating of mesoporous HZSM-5 with silicalite-1 reduced the coking propensity

\section{ABSTRACT}

Catalytic treating of biomass fast pyrolysis vapors offers a promising route to convert many different types of lignocellulosic biomass into biofuels. Considerable research efforts have focused on using zeolite catalysts, especially the microporous HZSM-5 zeolite. Unfortunately, the zeolite's initial high activity in forming coke and light gases reduces the overall oil yield. In this contribution, we synthesized conventional HZSM-5 zeolite, mesoporous HZSM-5 zeolite, and a core-shell catalyst consisting of mesoporous HZSM-5 zeolite coated with a thin layer $(<20 \mathrm{~nm})$ of silicalite-1 zeolite. The catalysts were characterized by inductively coupled plasma optical emission spectroscopy (ICP-OES), X-ray diffraction (XRD), scanning electron microscopy (SEM), transmission electron microscopy (TEM), $\mathrm{N}_{2}$ and $\mathrm{Ar}$ physisorption, temperature programmed desorption of ammonia ( $\left.\mathrm{NH}_{3}-\mathrm{TPD}\right)$, diffuse reflectance infrared fourier transform spectroscopy (DRIFT) spectra, and ${ }^{27} \mathrm{Al}$ nuclear magnetic resonance (NMR). The catalysts were tested in a tandem micro-pyrolyzer system for deoxygenation of wheat straw derived fast pyrolysis vapors in a downstream catalytic fixed bed reactor and the quantitative product analysis was performed with GC-MS/FID/TCD and TGA-MS. The change in yields of different product groups was monitored during catalyst deactivation for an increasing number of pyrolysis vapor pulses and the cumulative carbon recoveries of all product streams (char, vapors, gas, and coke) were compared at different biomass-to-catalyst ratios $(\sim 4$ and $\sim 1)$ for catalyst loadings of 2 and $8 \mathrm{mg}$, 
respectively. In addition, the yields were compared for the same number of zeolitic acid sites. Even though the coking propensity was highest for the mesoporous HZSM-5 (5.1\% carbon recovery of fed biomass at $\mathrm{B}: \mathrm{C}=1)$, it showed improved conversion of oxygenates ( $\mathrm{wt} \% \mathrm{O}$ of vapors $=15$ ) and a higher tolerance towards deactivation by coking compared to the conventional HZSM-5 $(\mathrm{wt} \% \mathrm{O}$ of vapors $=20)$. Coating of mesoporous HZSM-5 with silicalite-1 reduced the number of acid sites per mass of catalyst by $\sim 20 \%$, which is attributed to the addition of the inert silicalite- 1 layer and passivation of the external acid sites of the mesoporous HZSM-5. Compared to mesoporous HZSM-5, the added silicalite-1 shell reduced the coke yield by $43 \%$ (from 5.1 to 2.9 $\mathrm{wt} \%$ of fed biomass carbon) for the same catalyst mass and by $8 \%$ ( $4.7 \mathrm{wt} \%$ of fed biomass carbon) for the same total number of acid sites. Furthermore, the tolerance towards deactivation observed for the mesoporous HZSM-5 core was largely preserved-especially for conversion of small oxygenates like acids, alcohols and aldehydes, resulting in vapors with $14 \mathrm{wt} \% \mathrm{O}$.

\section{ABBREVIATIONS}

AC, acids; ALC, alcohols; ALD, aldehydes; ALI, aliphatics; BTX, benzene, toluene and xylenes; CFP, catalytic fast pyrolysis; daf, dry and ash-free; DAR, diaromatics; d.b., dry basis; DTG, derivative thermogravimetry; EST, esters; FID, flame ionization detection; FUR, furans; GC, gas chromatography; KET, ketones; MAR, monoaromatics; MPH; methoxy-phenolics; MS, mass spectrometry; N, nitrogen containing compound; n.d., not determined; PH, phenolics; SUG, sugars; TEM, transmission electron microscopy; TGA, thermogravimetric analysis; TPD, temperature-programmed desorption;

KEYWORDS. Wheat Straw; Biomass; Catalytic Fast Pyrolysis; mesoporous HZSM-5;

Passivation; Core-Shell; Silicalite-1; 


\section{INTRODUCTION}

Integration of biomass-derived fast pyrolysis oils in existing oil refineries can decrease our dependence on crude oil and increase the share of renewables in the transport sector [1-4]. Fast pyrolysis processes are generally flexible with respect to biomass feedstocks [5-12]. Short gas residence times (less than $2 \mathrm{~s}$ ), high heating rates $\left(>500^{\circ} \mathrm{C} / \mathrm{s}\right)$, moderate temperatures $(400-700$ $\left.{ }^{\circ} \mathrm{C}\right)$, and low pressures $(1-5 \mathrm{~atm})$ are required to obtain a high oil yield. The pyrolysis oil contains hundreds of different oxygenated species, which—unfortunately—render the oil acidic and unstable. Catalytic deoxygenation of the biomass pyrolysis vapors prior to condensation reduces the acidity of the oil and improves its chemical stability, heating value, and miscibility with petroleum derived streams [13-17]. However, these improvements come at the expense of carbon loss as light hydrocarbons, $\mathrm{CO}, \mathrm{CO}_{2}$, and coke $[18,19]$. HZSM-5 zeolite is considered among the most suitable solid acid catalysts for the production of aromatics and gasoline range products from biomass derived pyrolysis vapors since the shape selective micropores $(\sim 5.5 \AA)$ improve the selectivity to aromatics and limit coke formation [20,21]. Nevertheless, rapid deactivation by coking occurs $[15,22]$.

Previous studies using small scale batch pyrolyzers and a variety of biomass feedstocks generally found that the introduction of mesopores to HZSM-5 zeolite lead to higher yield of monoaromatics while the influence on coke and gas yields was not always investigated or inconsistent results were reported across laboratories [23-26]. Testing mesoporous HZSM-5 zeolite at scales that allowed collection of liquid product indicated that the yield of coke increased for mesoporous HZSM-5 zeolite compared to its microporous version [27-30], but the tolerance towards deactivation by coke improved, leading to extended activity for deoxygenation and aromatization. When monitoring the change in vapor product distribution as function of increasing biomass-to-catalyst 
(B:C) ratio using an on-line mass spectrometer, Jia et al. [29] reported higher yields and a broader distribution of mono- and di-aromatics over the mesoporous HZSM-5 zeolite while for the conventional zeolite the yield of olefins and aromatic hydrocarbons decreased faster due to a faster deactivation.

While the introduction of auxiliary mesoporosity to HZSM-5 zeolite reduces the diffusion restrictions [25,31,32], it also increases the external acidity which lacks space confinements and therefore allows reactive oligomeric species and coke precursors to attach to these sites. The first attempts to limit the external acidity comprised the deposition of a $\mathrm{SiO}_{2}$ layer by chemical vapor [33,34] or liquid deposition [35-37], which successfully reduced the coke yields and increased the selectivity of p-xylene in the methanol-to-hydrocarbon (MTH) reaction [24] and biomass catalytic fast pyrolysis (CFP) [36]. Unfortunately, a significant reduction in total acidity [36] indicated that some pore entries were blocked by the randomly deposited $\mathrm{SiO}_{2}$ considering that the number of the external acid sites is much less than that of the internal acid sites [38]. Growing a shell of catalytically inactive aluminium-free silicalite- 1 zeolite with the same MFI zeolite framework as HZSM-5 zeolite along the external surface of HZSM-5 core crystal would reduce the external acidity while likely preserving the access and number of internal acid sites [39]. The applications of such core-shell HZSM-5/silicalite-1 materials have been demonstrated for simple reactants [4044]. With respect to catalytic fast pyrolysis of biomass, Hu et al. [38] recently tested a conventional HZSM-5 coated with silicalite-1 for upgrading of vapors from pine pyrolysis in a fixed bed (550 $\left.{ }^{\circ} \mathrm{C}\right)$ located ex-situ and reported increased yields of benzene, toluene and xylenes (BTX) and decreased coke yields after silicalite-1 coating. The performance of silicalite-1 coated mesoporous HZSM-5 for the MTH process and in-situ CFP was reported by Li et al. [45]. While an increased lifetime for the MTH reaction was observed, no obvious differences in product yields from CFP were observed apart from an increased p-xylene selectivity. 
The work of Li et al. [45] is among the first reports that investigate the performance of silicalite-1 coated mesoporous HZSM-5 for CFP of whole biomass. Unfortunately, catalyst deactivation at increasing $\mathrm{B}: \mathrm{C}$ ratios was not investigated and the tests were performed with direct contact between the catalyst and biomass (in-situ), which can lead to poisoning of acid sites by the biomass indigenous ash [46]. Transfer of alkali metals to the catalyst can be avoided by placing the catalyst downstream of the pyrolysis section $[15,16]$ (ex-situ), which allows for vapor-phase upgrading of agriculture residues like wheat straw with higher ash content and lower cost compared to woody biomass. To the best of our knowledge, the performance of silicalite-1 coated mesoporous HZSM5 in ex-situ CFP has not yet been reported. Since in ex-situ CFP the yield of carbonaceous deposits on the catalyst (coke) is determined separately from the char, the coking propensity of catalysts can be compared and correlated with their properties.

In this study, we synthesized conventional HZSM-5 zeolite (Conv-ZSM-5), mesoporous HZSM5 zeolite (Meso-ZSM-5), and a core-shell catalyst consisting of a core of mesoporous HZSM-5 zeolite coated with a shell of silicalite-1 zeolite (Shell-Meso-ZSM-5). The catalysts were characterized and tested in a tandem micro-pyrolyzer system for upgrading wheat straw derived fast pyrolysis vapors. Product analysis for the catalytic tests was performed with GC-MS/FID/TCD and TGA-MS. We established a correlation between the GC-FID response and the molecular properties of $\sim 50$ calibrated vapor compounds. From this correlation, the yield for all vapor compounds could be calculated based on their molecular properties. This approach allowed monitoring the change in the yields of different product groups due to catalyst deactivation for an increasing number of injected biomass samples. The importance of reporting carbon balance was recently stressed [18]. We therefore determined the carbon recoveries of all product streams (char, vapors, gas, and coke) and assessed the performance of the catalysts based on their product yields and tolerance towards deactivation. 


\section{EXPERIMENTAL SECTION}

\subsection{Feedstock}

The biomass feedstock was obtained by downsizing wheat straw pellets using a hammer mill. Ultimate and proximate characterization for wheat straw particles of the size $<1.4 \mathrm{~mm}$ was reported earlier [15]. In this study, a sieve fraction of 106-250 $\mu \mathrm{m}$ was used and re-analyzed. The elemental content was determined using an Elementar ${ }^{\circledR}$ elemental analyzer (vario MICRO cube) in CHNS operating mode (ultimate analysis). The temperature of the reduction and combustion tubes was set to $1050{ }^{\circ} \mathrm{C}$ and $850{ }^{\circ} \mathrm{C}$, respectively. A thermal conductivity detector (TCD) was used to quantify the amounts of carbon, hydrogen, nitrogen, and an infrared (IR) detector was used to quantify sulfur. Rice flour with known elemental composition was used for calibration, and the reported result represents the average from duplicate analysis. Based on the amount of combustion products and the dry and ash-free (daf) mass of samples loaded, the weight percentages of $\mathrm{C}, \mathrm{H}$, $\mathrm{N}, \mathrm{S}$, and $\mathrm{O}$ (by difference) were calculated to be $48.2 \%, 5.0 \%, 1.27 \%, 0.1 \%$, and $45.4 \%$, respectively.

Proximate analysis was conducted using a Mettler Toledo TG/DSC 1 following the procedure developed by Johnston [47]. About $30 \mathrm{mg}$ of biomass was loaded in alumina crucibles and the temperature was first ramped to $105^{\circ} \mathrm{C}$ at $10{ }^{\circ} \mathrm{C} / \mathrm{min}$ in a nitrogen atmosphere $(100 \mathrm{ml} / \mathrm{min})$ and held at that temperature for $40 \mathrm{~min}$ in order to determine moisture. For the analysis of volatiles, the temperature was ramped under the same flow conditions in $\mathrm{N}_{2}$ from 105 to $900{ }^{\circ} \mathrm{C}$ at $10{ }^{\circ} \mathrm{C} / \mathrm{min}$ and the temperature was held at $900{ }^{\circ} \mathrm{C}$ for $20 \mathrm{~min}$. For determination of the fixed carbon content, nitrogen was replaced by air and the temperature was held at $900{ }^{\circ} \mathrm{C}$ for $30 \mathrm{~min}$. The remaining mass after combustion of fixed carbon was considered ash. The moisture (as received (a.r.)), volatiles (dry basis, (d.b.)), ash (d.b.), and fixed carbon (d.b., by difference) were determined to be $7.1 \mathrm{wt}-\%, 74.4 \mathrm{wt}-\%, 9.8 \mathrm{wt}-\%$, and $15.8 \mathrm{wt}-\%$, respectively. 
Sulfuric acid hydrolysis was used for the determination of carbohydrates bound in the cellulose and hemicellulose. Klason lignin was determined as the ash free residue after hydrolysis. First, 1.5 $\mathrm{ml}$ of $72 \% \mathrm{H}_{2} \mathrm{SO}_{4}$ was added to $0.16 \mathrm{~g}$ sample and the sample was pre-hydrolyzed for 60 minutes at $30{ }^{\circ} \mathrm{C}$. Second, after dilution of the hydrolysate with MilliQ water $(42 \mathrm{ml})$, the liquid samples were autoclaved at $120{ }^{\circ} \mathrm{C}$ for 60 minutes. Filtered liquids were analyzed on an HPLC column, while the solid residue was heated to $550{ }^{\circ} \mathrm{C}$ to determine the lignin ash content. The content of carbohydrates and Klason lignin was determined to be $\sim 68.5 \mathrm{wt}-\%$ and $20.2 \mathrm{wt}-\%$, respectively. The contribution of individual carbohydrates is listed in Table S2.

\subsection{Catalyst preparation}

Used chemicals: Tetrapropylammonium hydroxide (TPAOH, Sigma-Aldrich, $1.0 \mathrm{M}$ in $\mathrm{H}_{2} \mathrm{O}$ ), tetraethylorthosilicate (TEOS, Sigma-Aldrich, $\geq 99.0 \%$ ), sodium aluminate $\left(\mathrm{NaAlO}_{2}\right.$, SigmaAldrich, anhydrous), carbon black particles (BP-2000) with average particle diameter of $12 \mathrm{~nm}$.

Conv-ZSM-5. The synthesis of ZSM-5 was based on the work of Thumbayil et al. [48]. $\mathrm{NaAlO}_{2}$ was dissolved in $7.2 \mathrm{ml}$ TPAOH before $4.4 \mathrm{ml}$ of TEOS was added dropwise (corresponding to nominal $\mathrm{Si} / \mathrm{Al}=40$ ) to the stirring solution. After 1 hour of stirring, the mixture was transferred to a Teflon-lined stainless steel autoclave and heated at $180^{\circ} \mathrm{C}$ for $24 \mathrm{~h}$. The product was washed with distilled water, calcined for $20 \mathrm{~h}$ at $550^{\circ} \mathrm{C}$ and ion exchanged to the proton form (see Ion exchange section).

Meso-ZSM-5. Following the procedure reported by Jacobsen et al. [49], carbon black was used to synthesize mesoporous ZSM-5. First, $\mathrm{NaAlO}_{2}$ was dissolved in $7.2 \mathrm{ml} \mathrm{TPAOH}$ and then $2 \mathrm{~g}$ of carbon black was impregnated with this solution and dried overnight at room temperature. The dried mixture was impregnated with $4.4 \mathrm{ml}$ of TEOS and dried overnight again at room temperature. Then the beaker was placed in a Teflon-lined stainless steel autoclave with distilled water around the beaker and heated at $180{ }^{\circ} \mathrm{C}$ for $72 \mathrm{~h}$. The product was washed with distilled 
water and calcined at $550{ }^{\circ} \mathrm{C}$ for $20 \mathrm{~h}$. This sample was also ion exchanged to the proton form (vide infra).

Shell-Meso-ZSM-5. Following previous work [50], the as-synthesized mesoporous ZSM-5 was impregnated first with TPAOH until incipient wetness in a Teflon beaker and dried overnight at room temperature and then with TEOS until incipient wetness and dried overnight at room temperature. The beaker was placed in a Teflon-lined stainless steel autoclave with distilled water around the beaker and heated at $180^{\circ} \mathrm{C}$ for $72 \mathrm{~h}$. The product was washed with distilled water and calcined at $550{ }^{\circ} \mathrm{C}$ for $20 \mathrm{~h}$. The final product was ion exchanged (see Ion exchange section).

Ion exchange. $1 \mathrm{~g}$ of zeolite was added to $80 \mathrm{ml}$ of $1 \mathrm{M}$ ammonium nitrate aqueous solution and stirring the solution at $80{ }^{\circ} \mathrm{C}$ for 1 hour. The process was repeated three times and the last ion exchange was carried out overnight. Finally, the zeolite was collected by centrifugation, washed with distilled water and calcined at $550{ }^{\circ} \mathrm{C}$ for $10 \mathrm{~h}$.

\subsection{Catalyst characterization}

Catalysts were characterized with powder X-ray diffraction in a Huber G670 diffractometer operated in transmission mode with $\mathrm{Cu} \mathrm{K \alpha l}$ irradiation from a focusing quartz monochromator with the scanning rate of $2 \% \mathrm{~min}$.

Scanning electron microscopy (SEM) was carried out on a Quanta 200 ESEM FEG operated at $20 \mathrm{kV}$ and transmission electron microscopy (TEM) was performed on a FEI Tecnai T20 G2 microscope operated at $200 \mathrm{kV}$ to investigate particle sizes and morphology of the catalyst samples.

$\mathrm{N}_{2}$ physisorption was carried out on a 3FLEX surface area and porosimetry analyzer at liquid nitrogen temperature. Prior to the measurement, samples were outgassed under vacuum at $400{ }^{\circ} \mathrm{C}$ overnight. The specific surface area $\left(S_{\mathrm{BET}}\right)$ was calculated by the BET method in the relative pressure range of 0.05 to 0.3 . The total pore volume $\left(V_{\text {total }}\right)$ was calculated from the amount of adsorbed nitrogen at the relative pressure of $p / p_{0}=0.95$. The $\mathrm{BJH}$ pore size distribution was derived 
from the adsorption branch of the $\mathrm{N}_{2}$ physisorption isotherm for calculation of the volume and surface area of mesopores (20-500 $\AA$ pore width).

A Quantachrome AsiQ instrument was used for Ar-physisorption measurements. Isotherms from Ar-physisorption were analyzed using the nonlinear density functional theory (NL-DFT) model applied to the adsorption branch of the isotherm.

Inductively coupled plasma optical emission spectroscopy (ICP-OES) was done for elemental analysis of the catalysts in an Agilent 720 ICP-OES spectrometer to determine the $\mathrm{Si} / \mathrm{Al}$ ratios.

Temperature programmed desorption (TPD) of ammonia was performed in a Micromeritics Autochem II 2920. Samples were pre-treated at $550{ }^{\circ} \mathrm{C}$ (heating ramp: $20{ }^{\circ} \mathrm{C} / \mathrm{min}$ ) in $20 \mathrm{~mL} / \mathrm{min}$ $\mathrm{He}$ for $1 \mathrm{~h}$ to remove moisture. The zeolites were then cooled to $100{ }^{\circ} \mathrm{C}$ and $\mathrm{NH}_{3}$ was adsorbed for $30 \mathrm{~min}\left(20 \mathrm{~mL} / \mathrm{min}\right.$ of $10 \mathrm{vol} \% \mathrm{NH}_{3}$ in $\left.\mathrm{He}\right)$ followed by a flowing He purge for $30 \mathrm{~min}$. $\mathrm{The}^{\mathrm{NH}_{3}}$ desorption while heating the samples to $600{ }^{\circ} \mathrm{C}$ using a $10{ }^{\circ} \mathrm{C} / \mathrm{min}$ ramp in $10 \mathrm{~mL} / \mathrm{min} \mathrm{He}$ was recorded by a thermal conductivity detector (TCD). Curves were normalized using the sample mass. Based on a duplicate analysis, a standard deviation of $0.009 \mathrm{mmol} \mathrm{NH}_{3} / \mathrm{g}$ was calculated.

Diffuse reflectance infrared Fourier transform spectroscopy (DRIFT) of pyridine-loaded samples was performed on a Bruker Tensor 27 spectrometer equipped with a Harrick Praying Mantis attachment and a high temperature reaction chamber. The calcined zeolite samples were diluted to $4 \mathrm{wt}-\%$ in $\mathrm{KBr}$ (stored at $80{ }^{\circ} \mathrm{C}$ ) and mixed and ground thoroughly with a mortar and pestle to pass a $56 \mu \mathrm{m}$ sieve. Absorbance from 4000 to $400 \mathrm{~cm}^{-1}$ was collected using 64 scans at a $4 \mathrm{~cm}^{-1}$ resolution. A background spectrum was recorded with pure $\mathrm{KBr}$ at $150^{\circ} \mathrm{C}$. Prior to pyridine adsorption, the $\mathrm{KBr} / \mathrm{zeolite}$ mixture was heated to $450^{\circ} \mathrm{C}$ and held at the final temperature for $1 \mathrm{~h}$ under $30 \mathrm{ml} / \mathrm{min}$ Ar flow to remove moisture. The sample was cooled to $150^{\circ} \mathrm{C}$ under continued Ar flow. At $150{ }^{\circ} \mathrm{C}$, a three-way valve was switched to redirect the flow through a bubbler filled with pyridine kept at room temperature and the exiting gas stream was passed through the sample 
for $30 \mathrm{~min}$. After pyridine adsorption, the sample was flushed with $\mathrm{Ar}$ for 20 min to remove any weakly absorbed species before acquiring the DRIFT spectra. Subsequently, the temperature was increased to $250{ }^{\circ} \mathrm{C}$ and held for $30 \mathrm{~min}$, before acquiring the next spectrum. The procedure was repeated for higher temperatures of 350 and $450{ }^{\circ} \mathrm{C}$ as long as absorbance bands of pyridine adsorbed on Brønsted $\left(1545 \mathrm{~cm}^{-1}\right)$ and Lewis $\left(1455 \mathrm{~cm}^{-1}\right)$ acid sites were noticeable. The spectra were analyzed with OPUS 7.0 software, compensated for atmospheric $\mathrm{CO}_{2}$ and $\mathrm{H}_{2} \mathrm{O}$, baseline corrected, and smoothed. The peak height of the Lewis and Brønsted acid peaks at $150{ }^{\circ} \mathrm{C}$ was used to determine the ratio of Brønsted to Lewis acid sites (B/L).

The ${ }^{27} \mathrm{Al}$ NMR spectra were acquired with $8 \mathrm{k}$ scans $(8 \cdot 1024)$. The AVII-600 NMR spectrometer features a wide bore 14.1 tesla superconducting magnet and an Avance II spectrometer console from Bruker Corporation (Billerica, MA and Karlsruhe, Germany). The proton frequency for this field is $600.13 \mathrm{MHz}$ and the $27 \mathrm{Al}$ frequency is $156.38 \mathrm{MHz}$. All datasets were acquired with a rotor-synchronized Hahn echo pulse sequence (90-tau-180-tau-acquire) at $6 \mathrm{kHz}$ magic-angle spinning speed and a two rotor period tau delay ( $330 \mathrm{us)}$. The $90^{\circ}$ pulse was $2.5 \mu \mathrm{s}$ and the spectra were acquired under $62.5 \mathrm{kHz}$ proton decoupling. The free induction decay contained 1024 points with an acquisition time of $5.5 \mathrm{~ms}$ and a recycle delay of $1.5 \mathrm{~s}$. Resultant data were processed in TopSpin software (Bruker) using a Gaussian window function.

\subsection{Micro-pyrolyzer}

The experiments were carried out using a single-shot tandem micro-pyrolysis system (Rx3050tr, Frontier Labs, Japan) and analyzed by GC-MS/FID/TCD (see Fig. S1) using He as carrier gas at a flow rate of $60 \mathrm{~mL} / \mathrm{min}$ and a split ratio of 1:56. A detailed description of the experimental set-up can be found in the work of Nolte et al. [51]. The top pyrolysis reactor and the bottom catalytic reactor were maintained at $530{ }^{\circ} \mathrm{C}$ and $500{ }^{\circ} \mathrm{C}$, respectively. $0.59 \pm 0.1 \mathrm{mg}$ of wheat straw was loaded into calcined and reduced $\left(550^{\circ} \mathrm{C}\right)$ stainless steel sample cups and the cups were 
introduced into the pyrolysis zone via an autosampler. The catalytic reactor, located ex-situ of the pyrolysis reactor, contained a quartz tube loaded with a mixture of $60 \mathrm{mg}$ quartz beads (150-215 $\mu \mathrm{m}$, acid washed and calcined at $550^{\circ} \mathrm{C}$ ) and the catalyst (2-11.5 mg, 36-125 $\left.\mu \mathrm{m}\right)$. The dilution of the catalyst with quartz beads prevented channeling or bypass flow and maintained similar bed lengths across different catalyst loadings. The catalyst bed was secured between two quartz wool plugs in order to be placed within the temperature-controlled isothermal zone of the tandemreactor.

\subsection{Product analysis}

The GC (Agilent 7890B) separation was completed using an initial oven temperature of $35^{\circ} \mathrm{C}$ for $7.5 \mathrm{~min}$ followed by ramping at $10{ }^{\circ} \mathrm{C} / \mathrm{min}$ to $300{ }^{\circ} \mathrm{C}$. Condensable species were separated using a medium polarity 1701 column (Agilent VF-1701 ms) and identified by MS (Agilent 5977A) and quantified using FID. The chromatograms were processed using MassHunter Workstation Software (Agilent) and the identification of mass spectra peaks was achieved by using the NIST library (Version 2.0 f). Calibration of the FID detector was performed for 54 model compounds of various functionalities (aromatics, acids, ketones, aldehydes, phenols, methoxyphenols, furans etc.) as listed in Table S1. The FID response factor of compounds not available for calibration was estimated based on the positive correlation (Fig. S2) between the FID response determined for the calibrated compounds and the molecular response factor (MRF) of each compound that was calculated based on its combustion enthalpy and molecular structure [52].

While each FID chromatogram comprised peaks of $>100$ compounds, the compounds were grouped into aliphatics (ALI), monoaromatics (MAR), di-aromatics (DAR), phenols (PH), aldehydes (ALD), acids (AC), ketones (KET), methoxy-phenols (MPH), furans (FUR), alcohols (ALC), and nitrogen containing compounds (N). Table S4 to S16 provide an overview of the compounds contained in each product group along with their respective MRF. 
The light gases and hydrocarbons were separated using a GasPro column (Agilent GS-GasPro) and quantified using TCD. Analysis of light gas species was conducted by calibrating the TCD detector of the GC. Calibration was performed by injection of increasing volumes of a gas mixture containing $\mathrm{CO}, \mathrm{CO}_{2}, \mathrm{C}_{1^{-5}}$ alkanes and $\mathrm{C}_{2-\varsigma}$ alkenes with a gas-tight $1 \mathrm{~mL}$ syringe and correlating the resulting TCD peak areas with the moles injected.

To test the repeatability of the product analysis, three biomass injections were performed replacing the catalyst with $2 \mathrm{mg}$ of $\mathrm{SiC}$ as highly inert material. Table S3 lists the individual product standard deviations based on these three repeated injections.

The char yields were determined gravimetrically by weighing the sample cups and biomass before and after fast pyrolysis in the micro pyrolyzer.

Coke yields were determined by combustion of the coke in a TGA (Netzsch STA449 F1) coupled with an MS (QMS 403 D Aëolos $\left.{ }^{\circledR}\right)$.The content of the quartz tubes (catalyst plus glass beads) was emptied in alumina crucibles. Using $40 \mathrm{ml} / \mathrm{min}$ total flowrate, the samples were first heated in Argon to $350{ }^{\circ} \mathrm{C}\left(10{ }^{\circ} \mathrm{C} / \mathrm{min}\right.$, held at $350{ }^{\circ} \mathrm{C}$ for $\left.5 \mathrm{~min}\right)$ in order to remove moisture. The gas was adjusted to 20 vol- $\%$ oxygen (balance Ar) and the temperature was held for an additional $5 \mathrm{~min}$ at $350{ }^{\circ} \mathrm{C}$ before ramping to $600{ }^{\circ} \mathrm{C}$ at $10{ }^{\circ} \mathrm{C} / \mathrm{min}$ and holding the final temperature for $10 \mathrm{~min}$. Besides the weight loss monitored during the coke combustion, the mass of carbon and hydrogen in the coke was obtained by recording the evolving $\mathrm{CO}, \mathrm{CO}_{2}$ and $\mathrm{H}_{2} \mathrm{O}$ during combustion with the MS. The response of the MS detector for $\mathrm{CO}, \mathrm{CO}_{2}$ and $\mathrm{H}_{2} \mathrm{O}$ was calibrated by decomposition of a known amount of calcium oxalate (Sigma-Aldrich, $99.999 \%$ trace metal basis) when ramping the temperature at $20{ }^{\circ} \mathrm{C} / \mathrm{min}$ to $900{ }^{\circ} \mathrm{C}$ in $40 \mathrm{ml} / \mathrm{min}$ Ar. The relative deviation between the mass loss determined by TGA and the sum of the mass of $\mathrm{H}$ and $\mathrm{C}$ contained in the combustion gas species was less than $10 \%$, indicating that the carbon content of coke was $\sim 90 \%$. 


\section{RESULTS}

\subsection{Catalyst properties}

Powder X-ray diffraction results confirm the crystallinity of zeolite samples synthesized in this work. All zeolite samples show characteristic diffraction peaks of MFI structure at $7.9^{\circ}, 8.8^{\circ}, 23^{\circ}$, $23.9^{\circ}$ and $24.4^{\circ}$ (see Fig. S3), confirming the high crystallinity of the synthesized catalysts [53]. Since silicalite-1 and HZSM-5 have the same MFI topology structure, no additional XRD peaks were observed after coating with a shell of silicalite-1 zeolite.

Table 1 provides an overview of the physicochemical properties of the three catalysts tested in this study. Applying the NL-DFT model to the adsorption branch of the isotherm from highresolution low temperature Argon pore characterization (Fig. S5) shows that Meso-ZSM-5 contained smaller mesopores in the range of 30-100 A but also a large amount of mesopores $>100$ $\AA$. After silicalite-1 coating the amount of larger mesopores $>100 \AA$ decreased, while a shift towards smaller mesopores was observed. A likely explanation for this observation could be that the silicalite-1 coating (partly) filled mesopores. Thus, it can be expected that acid sites that were located in the mesopores were successfully covered.

Nitrogen physisorption (Fig. S4-A) shows that there is a steep nitrogen uptake at partial pressures up to $\mathrm{p} / \mathrm{p}_{0}=0.01$, which is an evidence for presence of micropores in all three samples with MFI structures. Conv-ZSM-5 zeolite has the characteristic type I isotherm (according to IUPAC classification) characteristic for microporous materials [54,55]. Meso-ZSM-5 zeolite showed a type IV isotherm with a hysteresis loop at approximately $p / p_{0}=0.85$. This observed hysteresis loop with upward curvature is known to be caused due to the presence of mesopores [56,57]. The coreshell zeolite similarly shows a type IV isotherm but a different hysteresis loop, of type H2. This hysteresis loop has a sharp closure at relative pressure of 0.45 that indicates the presence of inkbottle pores [58]. The inkbottle phenomenon indicates encapsulated mesopores inside the microporous shell. The sharp peak at $\sim 40 \AA$ pore width observed for Shell-Meso-ZSM-5 when 
deriving the $\mathrm{BJH}$ pore distribution from the desorption branch (see Fig. S4-B+C) is considered an artifact based on the tensile strength effect [59]. For Meso-ZSM-5, the BJH analysis (Fig. S4-B) reveals that the width of mesopores is between 100-500 $\AA$.

While the microporous volume was in the range of $0.18-0.19 \mathrm{cc} / \mathrm{g}$ for the three catalysts, clear differences in mesoporous volume $\left(V_{\text {meso }}\right)$ were observed. Ar-physisorption indicated that MesoZSM-5 zeolite had $0.28 \mathrm{cc} / \mathrm{g}$ compared to only $0.06 \mathrm{cc} / \mathrm{g}$ for the Conv-ZSM-5 zeolite. After silicalite-1 coating, $V_{\text {meso }}$ decreased to $0.11 \mathrm{cc} / \mathrm{g}$, which indicates that the addition of silicalite-1 filled some of the mesopores. Similar conclusions are derived from nitrogen physisorption data, for which $V_{\text {meso }}$ was determined to $0.08 \mathrm{cc} / \mathrm{g}$ for Conv-ZSM-5 and $V_{\text {meso }}$ decreased from $0.24 \mathrm{cc} / \mathrm{g}$ for Meso-ZSM-5 to $0.12 \mathrm{cc} / \mathrm{g}$ for Shell- Meso-ZSM-5, along with a decrease in total pore volume from 0.34 to $0.27 \mathrm{cc} / \mathrm{g}$ at $\mathrm{p} / \mathrm{p}_{0}=0.95$ (before the onset of interparticle nitrogen condensation).

SEM images show uniform particle size distribution for Conv-ZSM-5, which is less than 300 $\mathrm{nm}$, while the particle size of Meso-ZSM-5 is around $2000 \mathrm{~nm}$ (Fig. S6-A+B). From different TEM images (Fig. S8-C+D and Fig. S10) the thickness of the silicalite-1 layer is estimated to be less than $20 \mathrm{~nm}$. Based on the SEM images the addition of the thin shell did not have an observable effect on the particle size (Fig. S6-C).

Ammonia-TPD results (Fig. S11) show that Conv-ZSM-5 has less acid sites in comparison with the mesoporous ZSM-5 zeolite although these zeolites have similar Si/Al ratios based on ICP-OES results. The reason is speculated to be the limitations in the synthesis approach of conventional zeolite for low $\mathrm{Si} / \mathrm{Al}$ ratios that result in forming more extra-framework Al. As expected, by addition of the non-acidic silicalite-1 layer the overall concentration of acid sites in the material decreased for the core-shell ZSM-5 compared to the parent mesoporous ZSM-5. The effect of adding a silicalite-1 layer to the Meso-ZSM-5 is also observed in ICP-OES results as the Si/Al ratio increases from 53 in the Meso-ZSM-5 zeolite to 74 for the Shell-Meso-ZSM-5 zeolite. 
The Brønsted/Lewis (B/L) acid site ratio obtained from the pyridine DRIFT spectra was very similar amongst the catalysts: For conventional HZSM-5 and mesoporous HZSM-5 zeolites, the ratio was 6.4 , while the core-shell $\mathrm{HZSM}-5$ had $\mathrm{B} / \mathrm{L}=6.2$. When increasing the temperature, the adsorption band related to Lewis acid sites disappeared at temperatures above $250{ }^{\circ} \mathrm{C}$ (see Fig. S12). Brønsted acidity on the other hand extended to higher acid strength. Especially the MesoZSM-5 and Shell-Meso-ZSM-5 maintained a peak at $\sim 1530 \mathrm{~cm}^{-1}$ attributed to pyridine adsorbed on Brønsted acid sites for temperatures up to $450{ }^{\circ} \mathrm{C}$. For Conv-ZSM-5 zeolite, the strength of Brønsted acid sites appeared weaker as its peak had decreased appreciable at $350^{\circ} \mathrm{C}$.

A comparison of the ${ }^{27} \mathrm{Al}$ solid-state NMR spectra—scaled to the same peak areas—is shown in Fig. S13. The peak at $\sim 54 \mathrm{ppm}$ corresponds to framework $\mathrm{Al}$ in tetrahedral $\mathrm{AlO}_{4}$ and is an indirect measure for Brønsted acid sites. Peaks at 20-30 ppm and -5-10 ppm are both extra-framework aluminate (EFAL) domains corresponding to $\mathrm{AlO}_{5}$ and $\mathrm{AlO}_{6}$, respectively. Furthermore, the line shape give indications on the degree of local order/disorder around the Al nucleus, with highly ordered environments resulting in sharp peaks. Thus, the Conv-ZSM-5 zeolite showed both a higher fraction of EFAL (15.1\%) compared to Meso-ZSM-5 (7.8\%)/Shell-Meso-ZSM-5 (2.3\%) and a higher degree of disorder around the framework Al nucleus (see Fig. S13).

Table 1 Physicochemical characterization of the conventional HZSM-5, mesoporous HZSM-5, and silicalite-1 coated mesoporous HZSM-5 (core-shell). $V_{\text {micro }}$ and $S_{\text {micro }}$ were determined by high-resolution low temperature Argon physisorption $(87 \mathrm{~K})$, while all other textural parameters were derived from nitrogen adsorption data. Total acidity was determined by $\mathrm{NH}_{3}$-TPD.

\begin{tabular}{|l|c|c|c|}
\hline & Conv-ZSM-5 & Meso-ZSM-5 & Shell-Meso-ZSM-5 \\
\hline$V_{\text {micro }}{ }^{2}[\mathrm{cc} / \mathrm{g}]$ from Ar & 0.173 & 0.186 & 0.179 \\
\hline$S_{\text {micro }}\left[\mathrm{m}^{2} / \mathrm{g}\right]$ from $\mathrm{Ar}$ & 1310 & 1420 & 1360 \\
\hline$V_{\text {meso }}[\mathrm{ccc} / \mathrm{g}]$ from $\mathrm{N}_{2}$ & 0.077 & 0.242 & 0.123 \\
\hline$S_{\text {meso }}\left[\mathrm{m}^{2} / \mathrm{g}\right]$ from $\mathrm{N}_{2}$ & 71 & 81 & 80 \\
\hline$V_{\text {total }}$ at $\mathrm{p} / \mathrm{p}_{0}=0.95$ from $\mathrm{N}_{2}$ & 0.20 & 0.34 & 0.27 \\
\hline BET area $\left(\mathrm{N}_{2}\right)\left[\mathrm{m}^{2} / \mathrm{g}\right]$ & 375 & 426 & 419 \\
\hline
\end{tabular}




\begin{tabular}{|l|c|c|c|}
\hline Total Acidity $\left[\mathrm{mmol} \mathrm{NH}_{3} / \mathrm{g}\right]$ & 0.171 & 0.247 & 0.199 \\
\hline $\mathrm{B} / \mathrm{L} \mathrm{ratio}$ & 6.4 & 6.4 & 6.2 \\
\hline $\mathrm{Si} / \mathrm{Al}^{\mathrm{d}}$ & 51 & 53 & 74 \\
\hline
\end{tabular}

abtained from NL-DFT of adsorption branch; ${ }^{\mathrm{a}}$ obtained from BJH analysis of adsorption branch; 'determined from pyridine FT-IR; ' ${ }^{\mathrm{c}}$ calculated from ICP-OES results;

\subsection{Product distribution}

Non-catalytic reference. Table S17 shows the structure of the 34 most prevalent compounds identified in the vapors from fast pyrolysis of wheat straw at $530{ }^{\circ} \mathrm{C}$ without catalytic upgrading. Note that all compounds contain at least one oxygen functionality. Aldehydes (ALD), ketones (KET), and furans (FUR) had the highest number of group members with $5+$ members per group. Esters (EST) and methoxy-phenols (MPH) contained four members, respectively, while alcohols (ALC), sugars (SUG), acids (AC) and phenols (PH) contained 1-2 group members. PH and MPH are attributed to the decomposition of the lignin component of wheat straw, while anhydrosugars and smaller oxygenates result from the pyrolysis of hemicellulose and cellulose [60-62].

Catalyst vapor upgrading: The repeated injection of biomass cups allowed monitoring the change in product distribution for each injection and calculating integral yields at a certain cumulative weight ratio of injected biomass (daf) to loaded catalyst. Initially, the performance of the three catalysts was compared for catalyst loadings of $2 \mathrm{mg}$ and $8 \mathrm{mg}$, respectively. For a series of 16 biomass injections of $\sim 0.5 \mathrm{mg}$ daf wheat straw per injection, a cumulative B:C ratio of $\sim 4$ was reached when loading $2 \mathrm{mg}$ of catalyst, while $\mathrm{B}: \mathrm{C} \sim 1$ was reached when $8 \mathrm{mg}$ catalyst was loaded. Fig. S14 shows how the product yields of the different product groups developed with increasing amounts of biomass injected. With $2 \mathrm{mg}$ catalyst loading, Conv-ZSM-5 zeolite showed some initial activity by decreasing yields of oxygenates and increased MAR and DAR yields; however, its activity had decreased to a negligible level at $\mathrm{B}: \mathrm{C} \sim 1$ which can be attributed to catalyst deactivation by coking. Meso-ZSM-5 on the other hand showed significantly higher initial acidity and appeared more tolerant towards deactivation since the yield of MAR decreased less steeply and oxygenates continued to increase up to $\mathrm{B}: \mathrm{C} \sim 2.5$. After adding the silicalite-1 shell, 
the yield of MAR decreased slightly steeper compared to Meso-ZSM-5 and the yield of oxygenates continued to increase until $\mathrm{B}: \mathrm{C} \sim 2$. Table $\mathrm{S} 18$ compares the cumulative yields at $\mathrm{B}: \mathrm{C} \sim 4$ when using $2 \mathrm{mg}$ catalyst. Meso-ZSM-5 was most active as it achieved the highest yield of MAR (0.72 wt- $\%)$ and $\mathrm{C}_{2^{-}-3}$ olefins, concomitantly with achieving the lowest yield of acids (1.44 wt- $\left.\%\right)$ and methoxy-phenols (0.54 wt-\%) amongst the three catalysts. The higher activity of Meso-ZSM-5 agrees with its higher acidity and better accessibility of the actives sites (Table 1).

Increasing the catalyst loading to $8 \mathrm{mg}$ increased the conversion and therefore allowed for monitoring the differences in deactivation behavior up to $\mathrm{B}: \mathrm{C} \sim 1$ at a higher resolution. For ConvZSM-5 zeolite (Fig. S14b), the yield of MAR decreased in an exponential decay function, while the yield of oxygenates started to increase after the first injection. For Meso-ZSM-5 zeolite on the other hand, the MAR yields were almost stable for the first three injections after which the MAR yields decreased linearly indicating a high tolerance toward deactivation (see Fig. S14d). Likewise, the yield of oxygenates increased moderately and AC and MPH were completely converted up to B:C $\sim 0.5$. For the Shell-Meso-ZSM-5 material (Fig. S14f), the yield of MAR decreased slightly steeper. While MPH started to slowly break through above B:C $\sim 0.3$, acids were similarly effectively converted compared to Meso-ZSM-5. Table 2 provides an overview of the product yields obtained with $8 \mathrm{mg}$ of catalyst loading. Compared to a loading of $2 \mathrm{mg}$ catalyst (Table S18), the four times higher catalyst loading led to higher conversions as seen by the increased MAR yields and reduced yields of oxygenates like acids and methoxy-phenols when comparing the product yields at $\mathrm{B}: \mathrm{C} \sim 1$.Higher catalyst loading also increased gas formation, especially $\mathrm{CO}$ and ethylene/propylene. Note that while Shell-Meso-ZSM-5 showed similar performance as the mesoHZMS-5 in converting smaller oxygenates like ALD, AC, and ALC, it was least effective in converting MPH. This agrees with the fact that MPH are bulky compounds that cannot enter the 
micropore structure of HSZM-5 and therefore have to be converted at external acid sites, which were blocked by the inert silicalite-1 layer.

To obtain a comparison of the catalytic performance for the same number of acid sites, the reactor loading was adjusted to $11.54 \mathrm{mg}$ and $9.95 \mathrm{mg}$ for the Conv-ZSM-5 and the core-shell catalyst, respectively. Since the amount of biomass per injection was kept constant, the number of injections was increased from 16 to 20 and 23 for the core-shell and conventional HZSM-5, respectively. Fig. S15-S17 show a comparison of the FID chromatograms for the first and last injection of wheat straw over the three different catalysts, respectively. For all three catalysts, the main product species observed at the first injection $(B: C=0-0.05)$ were simple mono- and diaromatics like substituted benzenes, naphtenes, and naphtalenes, as well as small oxygenates like acetaldehyde, furan, and acetone. For the last injection close to B:C $\sim$, the peak height of MAR and DAR decreased and additional oxygenates were observed. However, clear differences in the extent of catalyst deactivation was observed when comparing the chromatograms at $\mathrm{B}: \mathrm{C} \sim 1$ amongst the different catalysts. This is in accordance with Fig. 1 monitoring the change in product yields with increasing biomass injections for the same number of acid sites. For all three catalysts, similar MAR yields of $\sim 8 \mathrm{wt}-\%$ were obtained for the first injection. The conventional HZSM-5 was the least efficient catalyst as seen by the rapid decline in aromatization activity and rapid breakthrough of oxygenates, whereas the oxygenates increased at a lower rate for Meso-ZSM-5 (Fig. 1b) and Shell-Meso-ZSM-5 (Fig. 1c). For Conv-ZSM-5 the AC and MPH started to break through at B:C $\sim 0.3$. For Meso-ZSM-5, on the other hand, the AC and MPH were completely converted until B:C $\sim 0.6$, and for the core-shell catalyst the breakthrough of MPH occurred earlier (0.5) while acids were effectively converted up to $\mathrm{B}: \mathrm{C} \sim 0.7$. Comparing the cumulative yields at $\mathrm{B}: \mathrm{C} \sim 1$ for the same number of acid sites (Table 2b) indicates that the Shell-Meso-ZSM-5 obtained the highest cumulative yield of MAR/DAR and the lowest yields of AC. 
A comparison of the monoaromatics selectivities for the different catalyst types is shown in Fig. S18. With increased catalyst loading to $8 \mathrm{mg}$, higher BTX selectivities were obtained compared to a loading of $2 \mathrm{mg}$ catalyst. No clear differences in the selectivities to different monoaromatic species could be discerned amongst the three catalysts, indicating similar shape selectivity of the bulk microporous volume. 

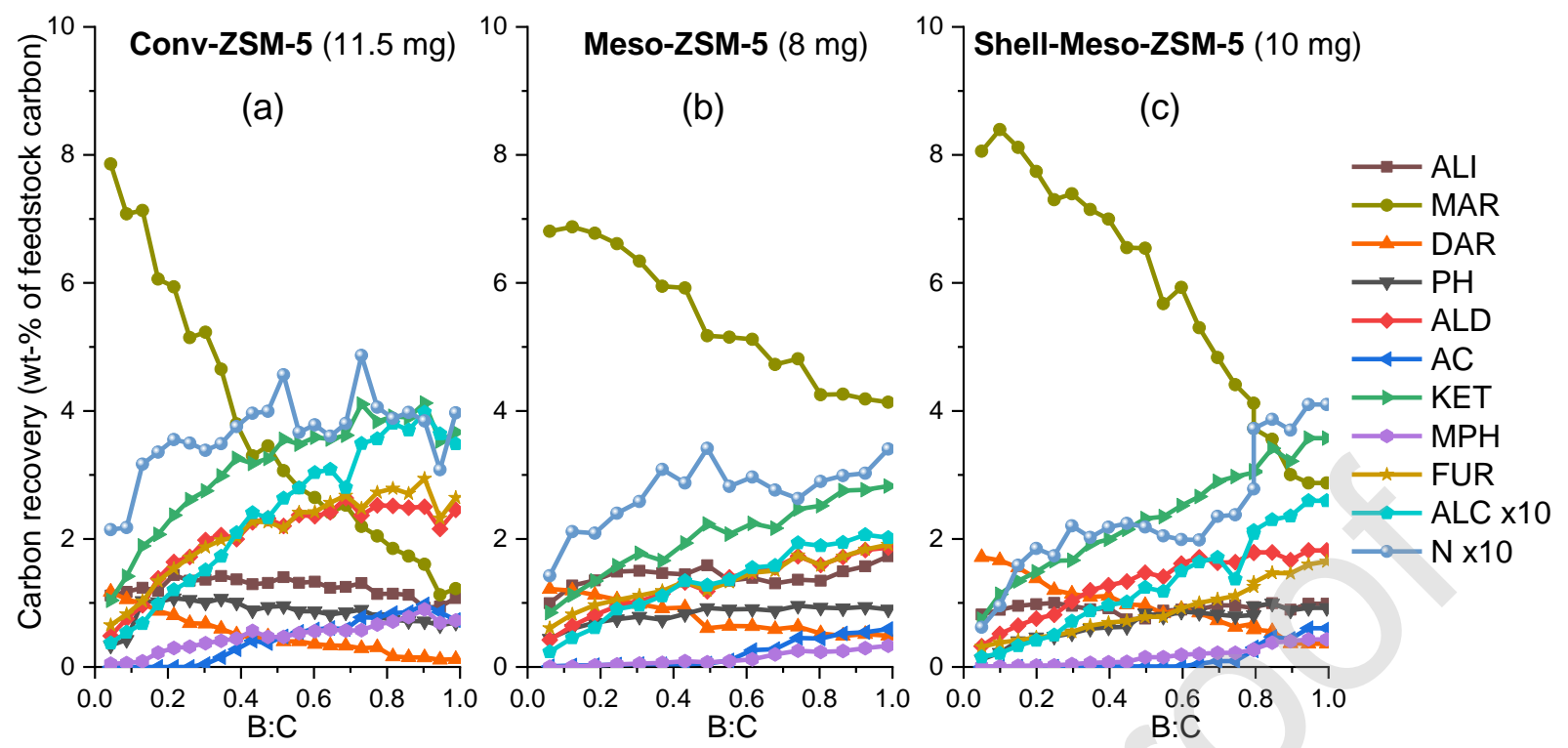

Fig. 1 Carbon yields of the different product groups for the same number of acid sites per reactor loading. The catalyst loading of conventional HZSM-5 (a) and silicalite-1 coated mesoporous HZSM-5 (c) was increased to $11.5 \mathrm{mg}$ and $10 \mathrm{mg}$ in order to match the number of acid sites of $8 \mathrm{mg}$ mesoporous HZSM-5 (b). Shown are the momentary carbon yields for each biomass injection. The abbreviations in the legend refer to aliphatics (ALI), monoaromatics (MAR), di-aromatics (DAR), phenols (PH), aldehydes (ALD), acids (AC), ketones (KET), methoxy-phenols (MPH), furans (FUR), alcohols (ALC), and nitrogen containing compounds $(\mathrm{N})$. The yield of ALC and $\mathrm{N}$ was multiplied by 10 for better visibility. 
Table 2 Yields of species at a cumulative fed dry and ash-free biomass to catalyst ratio of B:C $\sim 1$. Table 2a shows the yields obtained with $8 \mathrm{mg}$ of catalyst while Table $2 \mathrm{~b}$ shows the yield obtained for the same number of acids sites, for which the loading of conventional and core-shell catalysts was increased to 11.5 and $10 \mathrm{mg}$, respectively. Results obtained with $\mathrm{SiC}$ as a highly inert solid shown for reference. Vapors and gas were analyzed by GC-FID and GC-TCD, respectively.

\begin{tabular}{|c|c|c|c|c|c|c|c|c|c|c|c|c|c|c|c|c|c|}
\hline & \multicolumn{10}{|c|}{ Vapors } & \multicolumn{6}{|c|}{ Gas } \\
\hline & & ALI & MAR & DAR & $\mathrm{PH}$ & ALD & $\mathrm{AC}$ & KET & MPH & FUR & ALC & $\mathrm{N}$ & $\mathrm{CO}$ & $\mathrm{CO}_{2}$ & $C_{1-3}$ & $\begin{array}{c}\mathrm{C}_{2-3} \\
\text { olefins }\end{array}$ & $\mathrm{C}_{4}+$ \\
\hline \multirow{4}{*}{ (a) } & $\mathrm{SiC}$ & 0.06 & 0.04 & 0.00 & 0.13 & 1.76 & 2.44 & 3.91 & 0.88 & 1.05 & 0.75 & 0.00 & 7.1 & 17.1 & 0.1 & 0.3 & 0.3 \\
\hline & $\begin{array}{l}\text { Conv- } \\
\text { ZSM-5 }\end{array}$ & 0.88 & 1.22 & 0.08 & 0.38 & 1.66 & 0.90 & 2.49 & 0.11 & 1.37 & 0.33 & 0.33 & 8.4 & 17.2 & 0.1 & 0.6 & 0.6 \\
\hline & $\begin{array}{l}\text { Meso- } \\
\text { ZSM-5 }\end{array}$ & 0.78 & 2.87 & 0.41 & 0.51 & 1.11 & 0.26 & 1.52 & 0.09 & 0.90 & 0.15 & 0.21 & 10.3 & 18.0 & 0.0 & 1.3 & 1.0 \\
\hline & $\begin{array}{l}\text { Shell- } \\
\text { Meso- } \\
\text { ZSM-5 }\end{array}$ & 0.71 & 2.49 & 0.40 & 0.37 & 1.18 & 0.20 & 1.95 & 0.19 & 1.22 & 0.16 & 0.24 & 9.5 & 18.0 & 0.1 & 1.1 & 0.9 \\
\hline & & & & & & & & & & & & & & & & & \\
\hline \multirow{3}{*}{ (b) } & $\begin{array}{l}\text { Conv- } \\
\text { ZSM-5 }\end{array}$ & 0.68 & 1.95 & 0.26 & 0.53 & 1.68 & 0.51 & 2.34 & 0.33 & 1.41 & 0.29 & 0.28 & 12.6 & 20.0 & 0.1 & 2.6 & 1.3 \\
\hline & $\begin{array}{l}\text { Meso- } \\
\text { ZSM-5 }\end{array}$ & 0.78 & 2.87 & 0.41 & 0.51 & 1.11 & 0.26 & 1.52 & 0.09 & 0.90 & 0.15 & 0.21 & 10.3 & 18.0 & 0.0 & 1.3 & 1.0 \\
\hline & $\begin{array}{l}\text { Shell- } \\
\text { Meso- } \\
\text { ZSM-5 }\end{array}$ & 0.50 & 3.11 & 0.50 & 0.42 & 1.11 & 0.14 & 1.73 & 0.11 & 0.59 & 0.14 & 0.18 & 12.2 & 16.5 & 0.0 & 3.0 & 0.9 \\
\hline
\end{tabular}

Table S19 and Table 3a show a comparison of the carbon recoveries of vapors, gas, and coke when using 2 and $8 \mathrm{mg}$ of catalyst, respectively, while Table $3 \mathrm{~b}$ provides a comparison based on the same number of acid sites. Char yields of $18.3 \mathrm{wt}-\%( \pm 0.08)$ of fed wheat straw (daf) were determined, which is in agreement with char yields of 18-21 wt-\% (daf) observed for the same feedstock and pyrolysis temperature at a fast pyrolysis bench scale unit $[1,2]$. The amount of recovered char using the micropyrolyzer was insufficient to conduct proximate and elemental analysis. In view of the similar char yields observed at micro- and bench-scale, the elemental composition of the char from the micro-pyrolysis was assumed to be the same as determined in bench scale, namely 80 wt- $\%$ C, 4 wt- $\%$ H, 2 wt- $\%$ N, and 14 wt- $\%$ O (by difference) on a daf basis. Based on the estimated carbon content of char, the carbon recovery of char was $\sim 31 \mathrm{wt}-\%$ 
for all tests. As such, the carbon closure was in the range of $61 \mathrm{wt}-\%$ for the non-catalytic case, while it was improved to $\sim 81 \%$ when using a catalyst due to increased carbon recoveries of gas, vapors and coke. These observations agree with earlier work [6] which reported $\sim 90 \%$ carbon closure for pyrolysis of cellulose, lignin, and corn stover using the micro-pyrolyzer, while passing the vapors over an active catalyst increased the carbon closure to $\sim 100 \%$. We note that multiple peaks in the FID chromatogram with low intensity could not be identified and quantified properly and that the sum of these non-identified compounds may constitute an important fraction of the missing carbon. Moreover, the missing carbon is attributed to deposits of oligomeric species with highly reactive functionalities that may polymerize and deposit at the interface between the reactors $\left(300^{\circ} \mathrm{C}\right)$, the $\mathrm{GC}$-inlet $\left(270^{\circ} \mathrm{C}\right)$, and the guard column inlet (see Fig. S19). A comparison of Table S19 and Table 3 shows that an increase in catalyst loading increased the carbon recovery of gas and coke. The highest carbon losses to coke resulted for Meso-ZSM-5 (5.1 C wt- $\%$ at B:C 1), while the Conv-ZSM-5 showed the lowest coking propensity (Table 3).

The quality of the never-condensed vapors is expected to correlate to some extent with the quality of condensed bio-oils. Parameters regarded essential for the assessment of bio-oil quality are the oil's acidity, oxygen content, and effective hydrogen index (EHI). Those parameters were introduced for assessment of the quality of the never condensed vapors. The acidity of the vapors was defined as (mass of acids in vapors)/(mass of vapors) and is expected to correlate with the total acid number of the condensed vapors [16,17]. The oxygen content of the vapors-defined as (mass of oxygen in vapors)/(mass of vapors) - gives an indication on the effectiveness of deoxygenation and serves as an indicator for the chemical stability of bio-oils. When oxygen is released as water during the cracking of oxygenates in bio-oils over acidic catalysts, hydrogen is depleted which leads to enriched aromatics content in the products but also rapid coke formation. The effective hydrogen to carbon ratio (EHI) as defined by Chen et al. [63] can be used to assess 
the coking propensity of the product mixture. EHI is defined as $(\mathrm{H}-2 \mathrm{O}-3 \mathrm{~N}-2 \mathrm{~S}) / \mathrm{C}$, where $\mathrm{H}, \mathrm{C}$, $\mathrm{O}, \mathrm{N}$, and $\mathrm{S}$ are atoms per unit weight of sample of hydrogen, carbon, oxygen, nitrogen and sulfur, respectively.

Both Meso-ZSM-5 and Shell-Meso-ZSM-5 zeolite were significantly more effective in reducing the acidity as compared to the conventional HZSM-5 zeolite (see Table 3). The core-shell catalyst was most effective in reducing the acidity. Similar conclusions can be drawn for the overall oxygen content of the vapors as the core-shell catalyst reduced the oxygen content the most (from $37.1 \mathrm{wt}-$ $\%$ to $14 \mathrm{wt}-\% \mathrm{O}$ ) when comparing the catalysts at the same number of acid sites. The EHI index was lowest for Conv-ZSM-5( 1) and highest for Meso-ZSM-5 ( 1.1,) while it was 1.05-1.07 for the core shell catalyst.

Table 3. Comparison of carbon recoveries of vapors, gas, and coke for (a) the same catalyst mass and (b) the same number of acid sites at B:C $\sim 1$. Carbon recovery of char was $\sim 31 \mathrm{wt}-\%$. The table further compares the acidity, EHI, and oxygen content of the vapors and shows the molar $\mathrm{CO} / \mathrm{CO}_{2}$ ratio of the gas.

\begin{tabular}{|c|c|c|c|c|c|c|c|c|}
\hline \multicolumn{2}{|c|}{} & $\begin{array}{c}\text { C-\% } \\
\text { vapors }\end{array}$ & C-\% gas & $\begin{array}{c}\text { C-\% } \\
\text { coke }\end{array}$ & $\begin{array}{c}\text { Acidity vapors } \\
\text { (wt-\%) }\end{array}$ & $\begin{array}{c}\text { EHI } \\
\text { vapors }\end{array}$ & $\begin{array}{c}\text { wt-\% O } \\
\text { vapors }\end{array}$ & CO/CO 2 \\
\hline \multirow{4}{*}{ (a) } & SiC & 12.6 & 17.3 & $\sim 0$ & 22.1 & 0.67 & 37.1 & 0.66 \\
\cline { 2 - 10 } & Conv-ZSM-5 & 13.6 & 26.4 & 1.9 & 9.2 & 1.00 & 23.4 & 0.94 \\
\cline { 2 - 10 } & Meso-ZSM-5 & 13.9 & 30.5 & 5.1 & 2.9 & 1.09 & 14.7 & 1.09 \\
\cline { 2 - 9 } & Shell-Meso-ZSM-5 & 14.0 & 29.3 & 2.9 & 2.2 & 1.05 & 16.6 & 1.07 \\
\hline \multirow{8}{*}{ (b) } & Conv-ZSM-5 & 15.0 & 29.5 & 3.4 & 4.9 & 0.98 & 20.4 & 0.99 \\
\cline { 2 - 10 } & Meso-ZSM-5 & 13.9 & 30.5 & 5.1 & 2.9 & 1.09 & 14.7 & 1.09 \\
\cline { 2 - 9 } & Shell-Meso-ZSM-5 & 13.6 & 27.1 & 4.7 & 1.6 & 1.07 & 14.0 & 1.16 \\
\hline
\end{tabular}

\section{Discussion}

For the same mass of catalyst $(8 \mathrm{mg})$, more than twice as much carbon deposited on Meso-ZSM5 zeolite compared to Conv-ZSM-5 zeolite, whereas only $\sim 30 \%$ more carbon had deposited on the core-shell catalyst compared to Conv-ZSM-5 catalyst. From the derivative curves of the weight loss during coke combustion (Fig. S20), two peaks could be discerned. The low temperature peak below $\sim 475^{\circ} \mathrm{C}$ is sometimes referred to as 'soft' or 'thermal' coke. This peak is considered to 
contain higher $\mathrm{H} / \mathrm{C}$ ratios and more oxygenated compounds, mostly derived from lignin derivatives because of their greater ability to re-polymerize $[64,65]$. This soft coke is deposited on the mesoand macroporous structure of the catalyst and combusts more readily. The coke combusting at higher temperatures $\left(>500^{\circ} \mathrm{C}\right)$ is considered 'hard' or 'catalytic' coke which is mainly deposited inside the micropores. It is formed by cyclization, aromatization and condensation reactions of reactants and products $[66,67]$ and thus consists of less hydrogenated polyaromatic structures. Interestingly, coke deposited on the Conv-ZSM-5 and core-shell Meso-ZSM-5 catalysts showed similar contributions of low and high temperature coke. For Meso-ZSM-5, the contribution of catalytic coke was more pronounced, which could indicate that the micropores were filled with coke to a greater extent due to their better accessibility through the auxiliary mesopore network.

Li et al. [45] reported higher aromatic carbon yields close to $14 \%$ compared to maximum aromatic yields of $\sim 8 \mathrm{C}-\%$ observed in this study. The differences can likely be attributed to the different operating modes (in-situ vs. ex-situ), a higher catalyst temperature of $550{ }^{\circ} \mathrm{C}$ used by $\mathrm{Li}$ et al. [45], and the larger amounts of catalyst used to achieve full deoxygenation. The pronounced increase in para selectivity amongst xylenes observed by Li et al. [44] (from 28 to $84 \%$ ) could not be confirmed in this study when using a silicalite-1 coated Meso-ZSM-5 for ex-situ CFP.

$\mathrm{Hu}$ et al. [38] tested a core-shell catalyst of silicalite-1 coated conventional HZSM-5 and investigated the change in carbon yield of BTX and olefins with increasing amount of biomass fed. In agreement with our results, there were no obvious changes in the carbon yields of gas after catalyst modification. A slight decrease in BTX yields was reported after silicalite-1 coating. While these authors did not report the acidity of the catalysts, the tests were performed for a constant catalyst mass and thus it is very likely that the addition of the inert silicalite-1 layer had decreased the number of acid sites per reactor loading. For the core-shell catalyst used by Hu et al. [38], the carbon recovery of coke decreased by $22.1 \%$ (from $15.2 \%$ to $11.9 \%$ ) compared to the same mass 
of conventional HZSM-5. In our study, the addition of the silicalite-1 layer reduced the carbon losses to coke by $43 \%$ compared to the same mass $(8 \mathrm{mg}$ ) of Meso-ZSM-5. The even more pronounced effect may be attributed to the higher coking propensity of mesoporous HZM-5 compared to conventional HZSM-5 [30]. Comparing the coking propensity for the same total number of acid sites shows that the carbon recovery of coke decreased by $\sim 8 \%$ after silicalite- 1 addition.

\title{
5 Conclusion
}

Conventional ZSM-5 zeolite, mesoporous ZSM-5 zeolite and mesoporous ZSM-5 zeolite covered with a non-acidic silicalite-1 layer were synthesized. For the first time we tested mesoporous HZSM-5 coated with silicalite-1 for the deoxygenation of biomass fast pyrolysis vapors in ex-situ configuration and provide detailed product yields obtained using a micropyrolyzer. Moreover, the deactivation behavior of the core-shell catalyst was compared to a mesoporous and conventional HZSM-5 catalyst. Even though the coking propensity was highest for the mesoporous HZSM-5, it showed improved conversion of oxygenates and a higher tolerance towards deactivation by coke. Coating of mesoporous HZSM-5 zeolite with silicalite-1 reduced the number of acid sites per mass of catalyst by $\sim 20 \%$, which is attributed to the addition of the inert silicalite-1 layer and passivation of the external acid sites of the mesoporous HZSM-5. Compared to mesoporous HZSM-5, the added silicalite- 1 shell reduced the coke yield by $43 \%$ for the same catalyst mass and by $8 \%$ for the same total number of acid sites, while the tolerance towards deactivation observed for the mesoporous HZSM-5 core was largely preservedespecially for conversion of small oxygenates like acids, alcohols and aldehydes.

\author{
ASSOCIATED CONTENT
}

\section{Supporting Information}


Reactor scheme, List of calibrated compounds and molecular response factors, XRD patterns, sorption isotherms, TEM image of catalysts, $\mathrm{NH}_{3}$-TPD profiles, wheat straw analysis by sulfuric acid hydrolysis, experimental uncertainty for repeated injections, list of vapor compounds according to product group, instant and cumulative carbon yields of each vapor group, exemplar FID chromatograms, documentation of carbonaceous deposits observed at equipment, Selectivities of monoaromatics, Derivate curves of weight loss during combustion

\section{AUTHOR INFORMATION}

\section{Author Contributions}

The manuscript was written through contributions of all authors. All authors have given approval to the final version of the manuscript.

\section{Funding Sources}

Andreas Eschenbacher acknowledges funding by the Danish Energy Technology Development and Demonstration Program (EUDP project number 12454). Farnoosh Goodarzi and Søren Kegnæs would like to acknowledge funding from Haldor Topsøe A/S, Independent Research Fund Denmark (Grant Nos. 5054-00119 and 6111-00237) and Villum fonden (Grant No. 13158).

Alireza Saraeian and Brent H. Shanks would like to acknowledge funding from the Iowa Energy Center, Iowa Economic Development Authority and its utility partners under the grant number 17-IEC-002.

\section{Declaration of interests}

The authors declare that they have no known competing financial interests or personal relationships that could have appeared to influence the work reported in this paper. 
The authors declare the following financial interests/personal relationships which may be considered as potential competing interests:

\section{ACKNOWLEDGMENT}

The sulfuric acid hydrolysis of the biomass feedstock was conducted by Dr. Zsuzsa Sárossy at the Technical University of Denmark and her help is gratefully acknowledged. We further would like to thank Dr. Sarah Cady at Iowa State University for performing the ${ }^{27}$ Al NMR measurements. 


\section{REFERENCES}

[1] H.L. Chum, R.P. Overend, Biomass and renewable fuels, Fuel Process. Technol. 71 (2001) 187-195. doi:10.1016/S0378-3820(01)00146-1.

[2] M. Shemfe, S. Gu, B. Fidalgo, Techno-economic analysis of biofuel production via bio-oil zeolite upgrading: An evaluation of two catalyst regeneration systems, Biomass and Bioenergy. 98 (2017) 182-193. doi:10.1016/j.biombioe.2017.01.020.

[3] L. Faba, E. Díaz, S. Ordóñez, Recent developments on the catalytic technologies for the transformation of biomass into biofuels: A patent survey, Renew. Sustain. Energy Rev. 51 (2015) 273-287. doi:10.1016/j.rser.2015.06.020.

[4] M.S. Talmadge, R.M. Baldwin, M.J. Biddy, R.L. McCormick, G.T. Beckham, G.A. Ferguson, S. Czernik, K. Magrini, T.D. Foust, P.D. Metelski, C. Hetrick, M.R. Nimlos, A perspective on oxygenated species in the refinery integration of pyrolysis oil, Green Chem. 16 (2014) 407-453. doi:10.1039/C3GC41951G.

[5] G.W. Huber, A. Corma, Synergies between bio- and oil refineries for the production of fuels from biomass, Angew. Chemie - Int. Ed. 46 (2007) 7184-7201. doi:10.1002/anie.200604504.

[6] N. Tröger, D. Richter, R. Stahl, Effect of feedstock composition on product yields and energy recovery rates of fast pyrolysis products from different straw types, J. Anal. Appl. Pyrolysis. 100 (2013) 158-165. doi:10.1016/j.jaap.2012.12.012.

[7] C.W. Edmunds, E.A.R. Molina, N. Andre, C. Hamilton, S. Park, O. Fasina, S. Adhikari, S.S. Kelley, J.S. Tumuluru, T.G. Rials, N. Labbe, Blended Feedstocks for Thermochemical Conversion: Biomass Characterization and Bio-Oil Production From Switchgrass-Pine 
Residues Blends, Front. Energy Res. 6 (2018) 16. doi:10.3389/fenrg.2018.00079.

[8] K. Wang, O.D. Mante, J.E. Peters, D.C. Dayton, Influence of the Feedstock on Catalytic Fast Pyrolysis with a Solid Acid Catalyst, Energy Technol. (2016) 183-188. doi:10.1002/ente.201600254.

[9] D.L. Carpenter, T.L. Westover, S. Czernik, W. Jablonski, Biomass feedstocks for renewable fuel production: a review of the impacts of feedstock and pretreatment on the yield and product distribution of fast pyrolysis bio-oils and vapors, Green Chem. 16 (2014) 384-406. doi:10.1039/C3GC41631C.

[10] B. Rejai, S.C.S.C. Engineer, R.J. Evans, S. Chemist, P. Chemist, J.P. Diebold, P.C. Engineer, J.W. Scahill, S.C.S.C. Engineer, C. Conversion, The conversion of biobased feedstocks to liquid fuels through pyrolysis, in: Energy From Biomass Wastes Xv, INST GAS TECHNOLOGY, 1991: pp. 855-876.

[11] T.N. Trinh, P.A. Jensen, D.J. Kim, N.O. Knudsen, H.R. Sørensen, S. Hvilsted, Comparison of lignin, macroalgae, wood, and straw fast pyrolysis, Energy and Fuels. 27 (2013) 13991409. doi:10.1021/ef301927y.

[12] C.E. Greenhalf, D.J. Nowakowski, A.B. Harms, J.O. Titiloye, A. V. Bridgwater, A comparative study of straw, perennial grasses and hardwoods in terms of fast pyrolysis products, Fuel. 108 (2013) 216-230. doi:10.1016/j.fuel.2013.01.075.

[13] A. V. Bridgwater, Review of fast pyrolysis of biomass and product upgrading, Biomass and Bioenergy. 38 (2012) 68-94. doi:10.1016/j.biombioe.2011.01.048.

[14] R. French, S. Czernik, Catalytic pyrolysis of biomass for biofuels production, Fuel Process. 
Technol. 91 (2010) 25-32. doi:10.1016/j.fuproc.2009.08.011.

[15] A. Eschenbacher, P.A. Jensen, U.B. Henriksen, J. Ahrenfeldt, C. Li, J.Ø. Duus, U.V. Mentzel, A.D. Jensen, Impact of ZSM-5 deactivation on bio-oil quality during upgrading of straw derived pyrolysis vapors, Energy \& Fuels. 33 (2019) 397-412. doi:10.1021/acs.energyfuels.8b03691.

[16] A. Eschenbacher, P.A. Jensen, U.B. Henriksen, J. Ahrenfeldt, C. Li, J.Ø. Duus, U.V. Mentzel, A.D. Jensen, Deoxygenation of wheat straw fast pyrolysis vapors using HZSM-5, Al2O3 , HZSM-5/Al2O3 extrudates, and desilicated HZSM-5/Al2O3 extrudates, Energy \& Fuels. (2019) acs.energyfuels.9b00906. doi:10.1021/acs.energyfuels.9b00906.

[17] A. Oasmaa, D.C. Elliott, J. Korhonen, Acidity of biomass fast pyrolysis bio-oils, Energy and Fuels. 24 (2010) 6548-6554. doi:10.1021/ef100935r.

[18] A. Saraeian, M.W. Nolte, B.H. Shanks, Deoxygenation of biomass pyrolysis vapors: Improving clarity on the fate of carbon, Renew. Sustain. Energy Rev. 104 (2019) 262-280. doi:10.1016/j.rser.2019.01.037.

[19] R.H. Venderbosch, A critical view on catalytic pyrolysis of biomass, ChemSusChem. 8 (2015) 1306-1316. doi:10.1002/cssc.201500115.

[20] J. Jae, G.A. Tompsett, A.J. Foster, K.D. Hammond, S.M. Auerbach, R.F. Lobo, G.W. Huber, Investigation into the shape selectivity of zeolite catalysts for biomass conversion, J. Catal. 279 (2011) 257-268. doi:10.1016/j.jcat.2011.01.019.

[21] T.R. Carlson, G.A. Tompsett, W.C. Conner, G.W. Huber, Aromatic production from catalytic fast pyrolysis of biomass-derived feedstocks, Top. Catal. 52 (2009) 241-252. 
doi:10.1007/s11244-008-9160-6.

[22] P.A. Horne, P.T. Williams, The effect of zeolite ZSM-5 catalyst deactivation during the upgrading of biomass-derived pyrolysis vapours, J. Anal. Appl. Pyrolysis. 34 (1995) 6585. doi:10.1016/0165-2370(94)00875-2.

[23] J. Li, X. Li, G. Zhou, W. Wang, C. Wang, S. Komarneni, Y. Wang, Catalytic fast pyrolysis of biomass with mesoporous ZSM-5 zeolites prepared by desilication with $\mathrm{NaOH}$ solutions, Appl. Catal. A Gen. 470 (2014) 115-122. doi:10.1016/j.apcata.2013.10.040.

[24] D.P. Gamliel, H.J. Cho, W. Fan, J.A. Valla, On the effectiveness of tailored mesoporous MFI zeolites for biomass catalytic fast pyrolysis, Appl. Catal. A Gen. 522 (2016) 109-119. doi:10.1016/j.apcata.2016.04.026.

[25] T.C. Hoff, D.W. Gardner, R. Thilakaratne, J. Proano-aviles, R.C. Brown, J.P. Tessonnier, Elucidating the effect of desilication on aluminum-rich ZSM-5 zeolite and its consequences on biomass catalytic fast pyrolysis, Appl. Catal. A Gen. 529 (2017) 68-78. doi:10.1016/j.apcata.2016.10.009.

[26] G. Dai, S. Wang, Q. Zou, S. Huang, Improvement of aromatics production from catalytic pyrolysis of cellulose over metal-modified hierarchical HZSM-5, Fuel Process. Technol. 179 (2018) 319-323. doi:10.1016/j.fuproc.2018.07.023.

[27] Y.-K. Park, H. Ju, H. Su, J. Jeon, J. Kim, R. Ryoo, K. Jeong, Highly valuable chemicals production from catalytic upgrading of radiata pine sawdust-derived pyrolytic vapors over mesoporous MFI zeolites, "Applied Catal. B, Environ. 95 (2010) 365-373. doi:10.1016/j.apcatb.2010.01.015. 
[28] H.J. Park, K.H. Park, J.K. Jeon, J. Kim, R. Ryoo, K.E. Jeong, S.H. Park, Y.K. Park, Production of phenolics and aromatics by pyrolysis of miscanthus, Fuel. 97 (2012) 379384. doi:10.1016/j.fuel.2012.01.075.

[29] L.Y. Jia, M. Raad, S. Hamieh, J. Toufaily, T. Hamieh, M.M. Bettahar, G. Mauviel, M. Tarrighi, L. Pinard, A. Dufour, Catalytic fast pyrolysis of biomass: Superior selectivity of hierarchical zeolites to aromatics, Green Chem. $19 \quad$ (2017) 5442-5459. doi:10.1039/c7gc02309j.

[30] A. Eschenbacher, P.A. Jensen, U.B. Henriksen, J. Ahrenfeldt, S. Ndoni, C. Li, J.Ø. Duus, U.V. Mentzel, A.D. Jensen, Catalytic deoxygenation of vapors obtained from ablative fast pyrolysis of wheat straw using mesoporous HZSM-5, Fuel Process. Technol. 194 (2019) 106119. doi:10.1016/J.FUPROC.2019.106119.

[31] L. Bu, M.R. Nimlos, D.J. Robichaud, S. Kim, Diffusion of Biomass Pyrolysis Products in H - ZSM - 5 by Molecular Dynamics Simulations, J. Phys. Chem. C. 121 (2017) 500-510. doi:10.1021/acs.jpcc.6b10871.

[32] L. Bu, M.R. Nimlos, D.J. Robichaud, S. Kim, Diffusion of aromatic hydrocarbons in hierarchical mesoporous H-ZSM-5 zeolite, Catal. Today. 312 (2018) 73-81. doi:10.1016/j.cattod.2018.02.012.

[33] B. Zhang, Z. Zhong, P. Chen, R. Ruan, Microwave-assisted catalytic fast pyrolysis of biomass for bio-oil production using chemical vapor deposition modified HZSM-5 catalyst, Bioresour. Technol. 197 (2015) 79-84. doi:10.1016/j.biortech.2015.08.063.

[34] K. Tominaga, S. Maruoka, M. Gotoh, N. Katada, M. Niwa, HZSM-5 modified by silica CVD for shape-selective production of $p$-xylene: Influence of in situ and ex situ preparation 
conditions of the zeolite, Microporous Mesoporous Mater. 117 (2009) 523-529. doi:10.1016/j.micromeso.2008.07.033.

[35] H. Zhang, M. Luo, R. Xiao, S. Shao, B. Jin, G. Xiao, M. Zhao, J. Liang, Catalytic conversion of biomass pyrolysis-derived compounds with chemical liquid deposition (CLD) modified ZSM-5, Bioresour. Technol. 155 (2014) 57-62. doi:10.1016/j.biortech.2013.12.085.

[36] Y.T. Cheng, Z. Wang, C.J. Gilbert, W. Fan, G.W. Huber, Production of p-xylene from biomass by catalytic fast pyrolysis using ZSM-5 catalysts with reduced pore openings, Angew. Chemie - Int. Ed. 51 (2012) 11097-11100. doi:10.1002/anie.201205230.

[37] H. Zhang, S. Shao, M. Luo, R. Xiao, The comparison of chemical liquid deposition and acid dealumination modified ZSM-5 for catalytic pyrolysis of pinewood using pyrolysis-gas chromatography/mass spectrometry, Bioresour. Technol. 244 (2017) 726-732. doi:10.1016/j.biortech.2017.08.036.

[38] C. Hu, H. Zhang, R. Xiao, Catalytic fast pyrolysis of biomass over core-shell HZSM5@silicalite-1 in a bench-scale two-stage fluidized-bed/fixed-bed reactor, J. Anal. Appl. Pyrolysis. 136 (2018) 27-34. doi:10.1016/j.jaap.2018.11.005.

[39] A. Ghorbanpour, A. Gumidyala, L.C. Grabow, S.P. Crossley, J.D. Rimer, Epitaxial growth of ZSM-5@Silicalite-1: A core-shell zeolite designed with passivated surface acidity, ACS Nano. 9 (2015) 4006-4016. doi:10.1021/acsnano.5b01308.

[40] Y.-Q. Deng, W.-F. Zhou, H.-M. Lv, Y.-Y. Zhang, C.-T. Au, S.-F. Yin, Synthesis of HZSM5@silicalite-1 core-shell composite and its catalytic application in the generation of pxylene by methylation of toluene with methyl bromide, RSC Adv. 4 (2014) 37296-37301 doi:10.1039/C4RA04126G. 
[41] H. Teng, J. Wang, D. Chen, P. Liu, X. Wang, Silicalite-1 membrane on millimeter-sized HZSM-5 zeolite extrudates: Controllable synthesis and catalytic behavior in toluene disproportionation, $\quad$ J. $\quad$ Memb. $\quad$ Sci. $381 \quad$ (2011) 197-203. doi:10.1016/J.MEMSCI.2011.07.025.

[42] N. Li, Y.-Y. Zhang, L. Chen, C.-T. Au, S.-F. Yin, Synthesis and application of HZSM5 @ silicalite-1 core-shell composites for the generation of light olefins from $\mathrm{CH} 3 \mathrm{Br}$, $\begin{array}{lllll}\text { Microporous } & \text { Mesoporous } & \text { Mater. } & 227 & \text { (2016) }\end{array}$ doi:10.1016/J.MICROMESO.2016.02.017.

[43] K. Miyake, Y. Hirota, K. Ono, Y. Uchida , N. Nishiyama, Selective Production of Benzene, Toluene and $p$-Xylene (BT $p$ X) from Various $\mathrm{C}_{1-3}$ Feedstocks over ZSM-5/Silicalite-1 Core-Shell Zeolite Catalyst, ChemistrySelect. 1 (2016) 967-969. doi:10.1002/slct.201600172.

[44] M. Kustova, M.S. Holm, C.H. Christensen, Y.H. Pan, P. Beato, T.V.W. Janssens, F. Joensen, J. Nerlov, Synthesis and characterization of mesoporous ZSM-5 core-shell particles for improved catalytic properties, Elsevier B.V., 2008. doi:10.1016/S01672991(08)80161-9.

[45] M. Li, Y. Hu, Y. Fang, T. Tan, Coating Mesoporous ZSM-5 by Thin Microporous Silicalite1 Shell: Formation of Core/Shell Structure, Improved Hydrothermal Stability and Outstanding Catalytic Performance, Catal. Today. (2019). doi:10.1016/j.cattod.2019.02.041.

[46] V. Paasikallio, C. Lindfors, E. Kuoppala, Y. Solantausta, A. Oasmaa, J. Lehto, J. Lehtonen, Product quality and catalyst deactivation in a four day catalytic fast pyrolysis production 
run, Green Chem. 16 (2014) 3549-3559. doi:10.1039/c4gc00571f.

[47] P.A. Johnston, Thermochemical methylation of lignin to produce high value aromatic compounds, Iowa State University, 2017. https://lib.dr.iastate.edu/etd/15544.

[48] R. Pulikkal Thumbayil, J. Mielby, S. Kegnæs, Pd Nanoparticles Encapsulated in Mesoporous HZSM-5 Zeolite for Selective One-Step Conversion of Acetone to Methyl Isobutyl Ketone, Top. Catal. 62 (2019) 678-688. doi:10.1007/s11244-019-01153-6.

[49] C.J.H. Jacobsen, C. Madsen, J. Houzvicka, I. Schmidt, A. Carlsson, Mesoporous zeolite single crystals, J. Am. Chem. Soc. 122 (2000) 7116-7117. doi:10.1021/ja000744c.

[50] F. Goodarzi, I.P. Herrero, G.N. Kalantzopoulos, S. Svelle, A. Lazzarini, P. Beato, U. Olsbye, S. Kegnæs, Synthesis of mesoporous ZSM-5 zeolite encapsulated in an ultrathin protective shell of silicalite-1 for MTH conversion, Microporous Mesoporous Mater. 292 (2020) 109730. doi:10.1016/J.MICROMESO.2019.109730.

[51] M.W. Nolte, A. Saraeian, B.H. Shanks, Hydrodeoxygenation of cellulose pyrolysis model compounds using molybdenum oxide and low pressure hydrogen, Green Chem. 19 (2017) 3654-3664. doi:10.1039/c7gc01477e.

[52] J.D. Saint Laumer, E. Cicchetti, P. Merle, J. Egger, Quantification in Gas Chromatography Prediction of FID Response Factors from Combustion Enthalpies and Molecular Structures - Supporting Information.pdf, 82 (2010) 3-5.

[53] K.T. Højholt, A.B. Laursen, S. Kegnæs, C.H. Christensen, Size-selective oxidation of aldehydes with zeolite encapsulated gold nanoparticles, Top. Catal. 54 (2011) 1026-1033. doi:10.1007/s11244-011-9722-x. 
[54] M. Thommes, R. Guillet-Nicolas, K.A. Cychosz, Physical Adsorption Characterization of Mesoporous Zeolites, Mesoporous Zeolites Prep. Charact. Appl. (2015) 349-384. doi:10.1002/9783527673957.ch11.

[55] J. Mielby, J.O. Abildstrøm, F. Wang, T. Kasama, C. Weidenthaler, S. Kegnæs, Oxidation of bioethanol using zeolite-encapsulated gold nanoparticles, Angew. Chemie - Int. Ed. 53 (2014) 12513-12516. doi:10.1002/anie.201406354.

[56] A.H. Janssen, I. Schmidt, C.J.H. Jacobsen, A.J. Koster, K.P. de Jong, Exploratory study of mesopore templating with carbon during zeolite synthesis, Microporous Mesoporous Mater. 65 (2003) 59-75. doi:10.1016/j.micromeso.2003.07.003.

[57] J.O. Abildstrøm, M. Kegnæs, G. Hytoft, J. Mielby, S. Kegnæs, Synthesis of mesoporous zeolite catalysts by in situ formation of carbon template over nickel nanoparticles, $\begin{array}{lllll}\text { Microporous } & \text { Mesoporous } & \text { Mater. } & 225237\end{array}$ doi:10.1016/j.micromeso.2015.12.015.

[58] J.C. Groen, J. Pérez-Ramírez, Critical appraisal of mesopore characterization by adsorption analysis, Appl. Catal. A Gen. 268 (2004) 121-125. doi:10.1016/j.apcata.2004.03.031.

[59] J.C. Groen, L.A.A. Peffer, J. Pérez-Ramírez, Pore size determination in modified microand mesoporous materials. Pitfalls and limitations in gas adsorption data analysis, Microporous Mesoporous Mater. 60 (2003) 1-17. doi:10.1016/S1387-1811(03)00339-1.

[60] L. Negahdar, A. Gonzalez-Quiroga, D. Otyuskaya, H.E. Toraman, L. Liu, J.T.B.H.B.H. Jastrzebski, K.M. Van Geem, G.B. Marin, J.W. Thybaut, B.M. Weckhuysen, K.M. Van Geem, Characterization and Comparison of Fast Pyrolysis Bio-oils from Pinewood, Rapeseed Cake, and Wheat Straw Using13C NMR and Comprehensive GC $\times$ GC, ACS 
Sustain. Chem. Eng. 4 (2016) 4974-4985. doi:10.1021/acssuschemeng.6b01329.

[61] F. Ates, S. Tophanecioglu, A.E. Putun, The evaluation of mesoporous materials as catalyst in fast pyrolysis of wheat straw, Int. J. Green Energy. 12 (2015) 57-64. doi:10.1080/15435075.2014.889005.

[62] Q. Yang, S. Wu, Wheat straw pyrolysis analysis by thermogravimetry and gas chromatography-mass spectrometry., Cellul. Chem. Technol. 43 (2009) 123-131.

[63] N.Y. Chen, D.E. Walsh, L.R. Koenig, Fluidized Bed Upgrading of Wood Pyrolysis Liquids and Related Compounds., ACS Div. Fuel Chem. Prepr. 32 (1987) 264-275. doi:10.1021/bk1988-0376.ch024.

[64] B. Valle, P. Castaño, M. Olazar, J. Bilbao, A.G. Gayubo, Deactivating species in the transformation of crude bio-oil with methanol into hydrocarbons on a HZSM-5 catalyst, J. Catal. (2012). doi:10.1016/j.jcat.2011.10.004.

[65] M. Ibáñez, B. Valle, J. Bilbao, A.G. Gayubo, P. Castaño, Effect of operating conditions on the coke nature and HZSM-5 catalysts deactivation in the transformation of crude bio-oil into hydrocarbons, Catal. Today. (2012). doi:10.1016/j.cattod.2012.04.030.

[66] M. Guisnet, P. Magnoux, Organic chemistry of coke formation, Appl. Catal. A Gen. 212 (2001) 83-96. doi:10.1016/S0926-860X(00)00845-0.

[67] M. Guisnet, L. Costa, F.R. Ribeiro, Prevention of zeolite deactivation by coking, J. Mol. Catal. A Chem. 305 (2009) 69-83. doi:10.1016/j.molcata.2008.11.012. 